\title{
Mechanisms of Pannexin 1 (PANX1) Channel Mechanosensitivity and Its Pathological Roles
}

\author{
Kai Yang ${ }^{1, *}$, Zhupeng Xiao ${ }^{1}$, Xueai He ${ }^{1}$, Ruotong Weng ${ }^{1}$, Xinyue Zhao ${ }^{1}$ and Taolei Sun ${ }^{1,2, *}$ \\ 1 School of Chemistry, Chemical Engineering and Life Science, Wuhan University of Technology, \\ Wuhan 430070, China; 247312@whut.edu.cn (Z.X.); 291707@whut.edu.cn (X.H.); Weng_rt@163.com (R.W.); \\ xyz1667@163.com (X.Z.) \\ 2 State Key Laboratory of Advanced Technology for Materials Synthesis and Processing, Wuhan University of \\ Technology, Wuhan 430070, China \\ * Correspondence: kyang43@whut.edu.cn (K.Y.); suntl@whut.edu.cn (T.S.)
}

check for updates

Citation: Yang, K.; Xiao, Z.; He, X.; Weng, R.; Zhao, X.; Sun, T.

Mechanisms of Pannexin 1 (PANX1)

Channel Mechanosensitivity and Its Pathological Roles. Int. J. Mol. Sci. 2022, 23, 1523. https://doi.org/ $10.3390 /$ ijms 23031523

Academic Editor: Georg R. Zoidl

Received: 19 December 2021

Accepted: 27 January 2022

Published: 28 January 2022

Publisher's Note: MDPI stays neutral with regard to jurisdictional claims in published maps and institutional affiliations.

Copyright: (C) 2022 by the authors. Licensee MDPI, Basel, Switzerland. This article is an open access article distributed under the terms and conditions of the Creative Commons Attribution (CC BY) license (https:// creativecommons.org/licenses/by/ $4.0 /)$.

\begin{abstract}
Pannexins (PANX) were cloned based on their sequence homology to innexins (Inx), invertebrate gap junction proteins. Although there is no sequence homology between PANX and connexins (Cx), these proteins exhibit similar configurations. The PANX family has three members, PANX1, PANX2 and PANX3. Among them, PANX1 has been the most extensively studied. The PANX1 channels are activated by many factors, including high extracellular $\mathrm{K}^{+}\left(\left[\mathrm{K}^{+}\right]_{\mathrm{e}}\right)$, high intracellular $\mathrm{Ca}^{2+}\left(\left[\mathrm{Ca}^{2+}\right]_{\mathrm{i}}\right)$, Src family kinase (SFK)-mediated phosphorylation, caspase cleavage and mechanical stimuli. However, the mechanisms mediating this mechanosensitivity of PANX1 remain unknown. Both force-from-lipids and force-from-filaments models are proposed to explain the gating mechanisms of PANX1 channel mechanosensitivity. Finally, both the physiological and pathological roles of mechanosensitive PANX1 are discussed.
\end{abstract}

Keywords: pannexin; mechanotransduction; force-from-lipids model; force-from-filaments model; glaucoma; cancer

\section{An Introduction to Pannexins}

Pannexins (PANX) were cloned based on their sequence homology to innexins (Inx), invertebrate gap junction proteins [1]. It was initially proposed that PANX share many functional features with connexins (Cx), vertebrate gap junction proteins [1]. Although there is no sequence homology between PANX and Cx, these proteins exhibit similar configurations: they all have four $\alpha$-helical transmembrane (TM) domains, two extracellular loops (EL), one intracellular loop (IL), one intracellular N terminal (NT) and one intracellular C terminal (CT) [2]. The PANX family has three members, PANX1, PANX2 and PANX3. Among them, PANX1 and PANX3 are more similar to each other, while PANX2 has a long $\mathrm{CT}$ domain that affects its regulation, targeting and macromolecular interactions [2].

PANX1 mRNA and protein are widely expressed in many tissues, including the eye, liver, kidney and central nervous system (CNS) [3]. Northern blot analysis shows that PANX2 mRNA is highly enriched in the CNS. In addition, PANX2 protein is mainly located in cytoplasmic compartments [4]. PANX3 mRNA and protein are only found in skin and osteoblasts $[3,5,6]$. The expression of PANX1 and PANX2 is inversely regulated in the brain during development. PANX1 mRNA expression is highest in the embryo and decreases significantly in the adult, while the expression of PANX2 mRNA is low in the prenatal brain but increases considerably during adulthood [7]. Six recent studies using cryo-EM have revealed that the PANX1 channel forms a heptamer [8-13]. The structures of PANX2 and PANX3 have not yet been solved. PANX2 is proposed to form an octomer [14], while the oligomerization status of PANX3 remains unstudied. 


\section{Mechanisms of PANX1 Activation}

It has been shown that different modes of activation can induce PANX1 to form a pore with either high conductance or low conductance $[15,16]$. The pore configuration with low conductance occurs in response to voltage-dependent stimuli; it has a unitary conductance of $40-70 \mathrm{pS}$. Its current is mainly mediated by the movement of $\mathrm{Cl}^{-}$ions $[15,16]$. The pore configuration with high conductance is formed in the presence of a high extracellular $\mathrm{K}^{+}$ concentration $\left.\left(\left[\mathrm{K}^{+}\right]_{e}\right)\right)$, high intracellular $\mathrm{Ca}^{2+}$ concentration $\left(\left[\mathrm{Ca}^{2+}\right]_{\mathrm{i}}\right)$ and/or mechanical stress. Its unitary conductance is $400-500 \mathrm{pS}$. This configuration is usually associated with ATP release $[15,16]$. Although the cryo-EM structure of the PANX1 channel has been solved in several recent studies, it is only consistent with its $\mathrm{Cl}^{-}$-selective conformation. The narrowest width of the pore is around $9 \AA$, which only allows the flux of $\mathrm{Cl}^{-}$[8-12]. In order to act as an ATP release channel, the channel pore of PANX1 should be larger than the diameter of an effectively hydrated ATP molecule, which is around $12 \AA$ [17]; a $9 \AA$ pore is too small for ATP to pass. It is possible that an additional conformation of PANX1 is not captured in these cryo-EM studies. The specific activation mechanisms of PANX1 can be broadly categorized as:

1. $\left[\mathrm{K}^{+}\right]_{\mathrm{e}}$ : It has been found that the effect of $\left[\mathrm{K}^{+}\right]_{\mathrm{e}}$ on PANX1 is dose-dependent. A $\left[\mathrm{K}^{+}\right]_{\mathrm{e}}$ larger than $10 \mathrm{mM}$ induces PANX1 channel opening and a $\left[\mathrm{K}^{+}\right]_{\mathrm{e}}$ of $130 \mathrm{mM}$ activates the PANX1 channel over a wide range of voltages [18]. The mechanism by which high $\left[\mathrm{K}^{+}\right]_{\mathrm{e}}$ induces the opening of PANX1 channels remains unknown. PANX1 current is still activated even when voltage is clamped [18]. Instead, it is proposed that high $\mathrm{K}^{+}$-induced activation of PANX1 requires a direct interaction of $\mathrm{K}^{+}$with its first EL [19]. Mutations of amino acids (R75A, S82A, L94A) in the ELs of PANX1 change these responses [20]. However, recent results question the ability of high $\left[\mathrm{K}^{+}\right]_{\mathrm{e}}$ to activate PANX1; it has been found that the activation of PANX1 by $\mathrm{K}^{+}$is not observed in all cell types $[15,21]$.

2. $\left[\mathrm{Ca}^{2+}\right]_{\mathrm{i}}$ : PANX1 channels can be stimulated by $\mathrm{G} \alpha \mathrm{q}$-containing $\mathrm{G}$ protein-coupled receptors (GPCRs), including P2Y purinergic receptors [22] and ion channels [23-25]. This kind of channel activation is mediated by an increase in $\left[\mathrm{Ca}^{2+}\right]_{i}$. For example, fluid shear stress exerted by flowing blood induces the activation of Piezo1, which increases ATP release and NO production in endothelial cells. These effects are mediated in part by PANX channels activated by $\left[\mathrm{Ca}^{2+}\right]_{\mathrm{i}}[23]$. In addition, the alveolar epithelium in the lung comprises alveolar epithelial type I (ATI) and surfactant secreting type II (ATII) cells. In ATI cells, when mechanical tension is imposed upon the membrane, it triggers the activation of Piezo1 channels in the caveolae. The resulting $\mathrm{Ca}^{2+}$ influx leads to the opening of PANX1, which induces ATP release and stimulates the secretion of surfactants from ATII cells [24]. Recently, it has been proposed that a Piezo1-PANX1 complex mediates the stretch-induced ATP release in cholangiocytes. The Piezo1 channel senses the membrane stretch and increases $\left[\mathrm{Ca}^{2+}\right]_{\mathrm{i}}$, which activates PANX1 and releases ATP [25]. The mechanism of [ $\left.\mathrm{Ca}^{2+}\right]_{\mathrm{i}}$-induced PANX1 activation has been revealed by a recent study. It proposes that the increase in $\left[\mathrm{Ca}^{2+}\right]_{\mathrm{i}}$ induces the activation of $\mathrm{Ca}^{2+} /$ calmodulin-dependent protein kinase II (CaMKII), which phosphorylates the amino acid residue S394 of PANX1, resulting in its opening and ATP release [26].

3. Src family kinase (SFK)-mediated phosphorylation: In addition to being activated by multiple metabotropic receptors, PANX1 channels can also be opened by ionotropic receptors and chemokine receptors, including $\mathrm{N}$-methyl-D-aspartate receptor (NM$\mathrm{DAR})$ and tumor necrosis factor alpha (TNF $\alpha)$ [27-29], which is mediated by the SFK phosphorylation of PANX1 channels. In hippocampal neurons, anoxia induces the opening of PANX1 channels via NMDARs [30,31]. This anoxia-induced PANX1 current is reduced by D-APV (an NMDAR antagonist) as well as by PP2 (an SFK inhibitor). However, MK-801 (an NMDAR pore blocker) does not block PANX1 current, suggesting that ion permeation via NMDARs is not required for this mechanism of activation of PANX1 channels. Instead, NMDARs activate the PANX1 channel 
metabotropically via SFKs [31,32]. A possible Src phosphorylation site on PANX1 channels is located at Tyr308. Activation of NMDARs increases the phosphorylation of Tyr308 in the presence of PP2 or a PANX1 mutant, which cannot be phosphorylated at Tyr308; the NMDAR-dependent increase at Tyr308 is abolished in cells [32]. SFKs are also involved in the activation of PANX1 channels induced by $\mathrm{TNF} \alpha$ in human umbilical vein endothelial cells (HUVECs). TNF $\alpha$-induced PANX1 opening requires the activation of type-1 TNF receptors and downstream signaling pathways through SFKs [29]. Further, the application of TNF $\alpha$ increases the phosphorylation of Tyr198 in PANX1 channels, and this increase is inhibited by PP2 [29], suggesting that the Tyr198 of PANX1 is a target of SFK phosphorylation in response to TNF $\alpha$ stimulation.

4. Caspase cleavage: At basal conditions, the C-terminus of PANX1 interacts with the channel pore and prevents channel activation. During apoptosis, after caspase 3/7 is activated, it cleaves the C-terminus of PANX1, resulting in constitutive activation of the channel [33]. Even without the occurrence of apoptosis, the direct application of constitutively activated caspase $3 / 7$ also potentiates PANX1 channels, suggesting that the cleavage directly regulates channel opening without the involvement of other apoptotic mediators [34]. In addition, the isolated CT tail of PANX1 blocks the channel pore [34]. Caspase 11 also activates the PANX1 channel by cleavage, which is involved in lipopolysaccharide (LPS)-induced pyroptosis in bone marrow-derived macrophages (BMDMs) [35].

5. Mechanical stimulation: PANX1 channels can also be stimulated by a wide range of mechanical stresses. In Xenopus oocytes injected with the cDNA of human PANX1, the PANX1 channel is activated mechanically by suction applied to a patch pipette. The increased channel activity occurs over a wide range of holding potentials when stressed mechanically [36]. The authors also showed that the activation of PANX1 can release ATP [36]. Subsequently, this mechanical sensitivity of PANX1 has been identified in other cells, including erythrocytes, lung epithelium and neurons [37-40]. Further, PANX1 is activated when cancer cells are subjected to deformation as they travel along the microvasculature, which contributes to cancer metastasis [41]. Moreover, focused ultrasound (FUS) can stimulate ER-localized mechanosensitive PANX1 and result in the release of $\mathrm{Ca}^{2+}$ from the ER in invasive cancer cells [42].

\section{Gating Mechanisms of PANX1 Channel Mechanosensitivity}

There are at least two independent gating mechanisms for PANX1 channels. One is mediated by its CT region; this gating mechanism is well studied. The CT region blocks the main pore of PANX1 via a ball and chain mechanism. It acts as a pore plug that can be moved away or cleaved, resulting in opening of the channel [34]. Consistently, the comparison between cryo-EM images of native PANX1 and CT-deleted PANX1 reveals that the conformation of the channel is not affected by cleavage of the C-terminus. In addition, progressive deletion of the CT region of PANX1 channels causes their stepwise activation, along with graded changes in single-channel conductance and ATP/dye permeation of PANX1 [21]. A second gating mechanism acts through the side tunnels of PANX1. PANX1 protein is a heptamer; side channels are formed by the shallow crevice between the upper intracellular domains (ICDs) of protomers. They have connections to the main pore and are gated by a linker between the NT helix and the first TM helix [13], but the structural mechanism for PANX1 mechanosensitivity has not been revealed by recent cryo-EM studies [8-13].

Along with structural and biophysical studies of disparate families of mechanosensitive ion channels, our understanding of PANX mechanosensitivity is developing rapidly. Two classic models for the mechanosensitive gating of PANX have been proposed, the force-from-lipids model and the force-from-filaments model. Recently, a third model has been suggested; in this hybrid model, the mechanotransduction of PANX is induced by both lipids and the cytoskeleton. 


\subsection{Force-from-Lipids Model}

The force-from-lipids model proposes that the channel is opened by the force transmitted through the lipid bilayer directly, without the involvement of the cytoskeleton or extracellular matrix $[43,44]$. After the ion channel is purified and reconstituted in a lipid bilayer, if it can be mechanically activated, then it can be considered "inherently mechanosensitive". In vitro liposome reconstitution has become a gold standard for identifying inherently mechanosensitive ion channels [45]. This model of PANX activation is supported by the PANX1 channel in excised membrane patches being activated by negative pressure (acting through a patch pipette by suction) [36,37].

The core mechanical force for gating mechanosensitive ion channels is generated by a change in the transbilayer pressure profile of the lipid bilayer. The anisotropy of the transbilayer pressure profile is determined by three factors. One is the repulsion between the hydrophilic lipid heads. The second is the steric repulsion among the lipid tails, which depends on the degree of lipid saturation. The third is the attraction between phospholipid molecules at the water-lipid interface, caused by the hydrophobicity of the phospholipid tails. This force prevents water molecules from entering the lipid bilayer [46]. In an idealized lipid bilayer with two identical monolayers, the transbilayer pressure profile is usually symmetric. There are negative peaks at the water-lipid interface and repulsive positive peaks in both the head and tail regions. The presence of a mechanosensitive ion channel will induce the pressure profile to become asymmetric [47]. Reciprocally, an asymmetric pressure profile could affect the activity of mechanosensitive ion channels.

The change in asymmetric pressure profile can be caused by either hydrophobic mismatch or bilayer curvature. Hydrophobic mismatch is induced by stretching a bilayer [48]. When the bilayer stretches, the membrane thins and causes hydrophobic mismatch between the membrane-facing domains of ion channels and the bilayer, which opens ion channels (Figure 1A) [46]. Bilayer curvature is generated by the asymmetric insertion of amphipaths into lipid bilayers (Figure 1A) [43,49]. The activity of many mechanosensitive channels, including Piezo1 and small-conductance mechanosensitive channel (MscS), can be modulated by these amphipathic molecules [46].
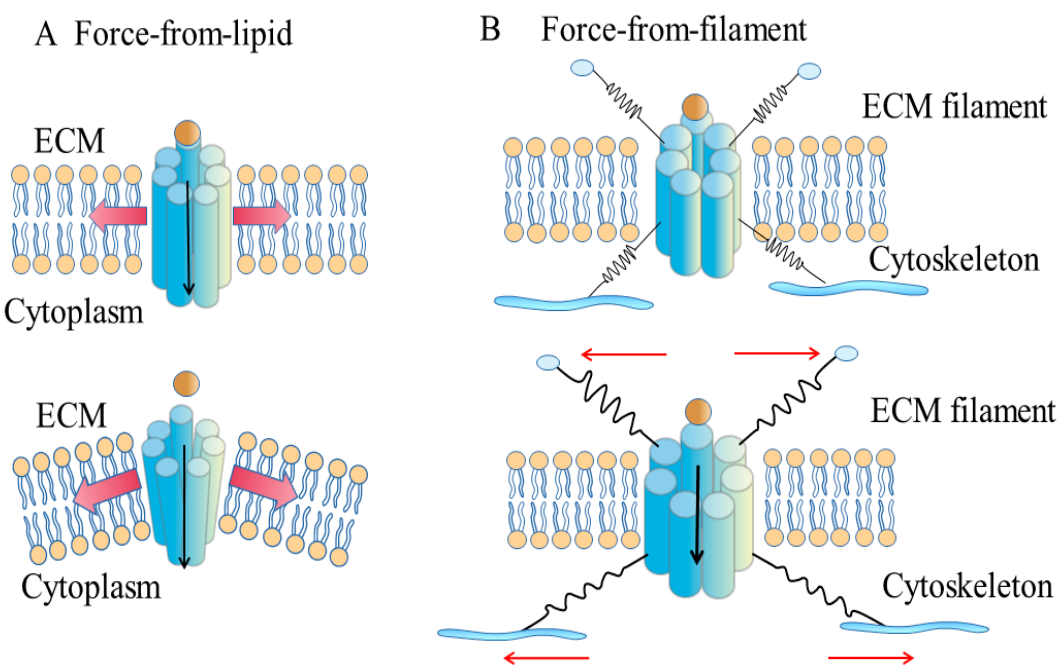

Figure 1. Two gating models of the mechanosensitive PANX1 channel. A. Force-from-lipids model. The PANX1 channel is opened by the force transmitted through the lipid bilayer directly, without the involvement of the cytoskeleton or extracellular matrix. The core mechanical force for gating PANX1 is generated by the change in the transbilayer pressure profile of the lipid bilayer, which includes both hydrophobic mismatch and bilayer curvature. Hydrophobic mismatch can be induced by stretching a bilayer, while bilayer curvature is generated by the asymmetric insertion of amphipaths into lipid bilayers. B. Force-from-filaments model. The PANX1 channel is gated via the cytoskeleton or extracellular matrix, which interacts with the PANX1 channel. 
The transbilayer pressure profile can be determined using either computational simulations [50] or experimental measurement [51]. When lipids with a different degree of unsaturation are incorporated into the phospholipids of cells, they have the ability to modulate the transbilayer pressure profile, which influences the ability of mechanical stress to activate mechanosensitive ion channels in the membrane. For example, the calculated value of the intra-bilayer pressure in the lipid bilayer is $250 \mathrm{~atm}$ for monounsaturated (18:1) lipids, while it is 350 atm for polyunsaturated (18:2 and 18:3) lipids [47,50]. These values have also been confirmed by NMR spectroscopy [51]. Consistently, depending on their chain length and degree of unsaturation, fatty acids have the ability to regulate PANX1 gating differentially. Acute application of saturated fatty acids (SFAs), such as palmitic acid (PA) (16:0) and stearic acid (SA) (18:0), in human and rat liver cell lines significantly potentiates PANX1 channel activity [52]. PA can also open the PANX1 channel in human renal tubule epithelial cells (HK-2 cells) [53]. In addition, upon exposure to palmitate, in macrophages, PANX1 is opened and releases nucleotides to attract neutrophils [54]. PANX3 has the same role in L6 myotubes [55]. The effect of monounsaturated FAs on the PANX1 channel is quite complex. In human and rat liver cell lines, neither palmitoleic acid (PO) (16:1) nor oleic acid (OA) (18:1) modulates PANX1 channel activity [52]. However, in bovine polymorphonuclear leukocyte cells (PMN), OA induces PANX1 opening, resulting in the formation of neutrophil extracellular traps (NETs) and the release of extracellular ATP [56]. Polyunsaturated FAs can either reduce or potentiate PANX1 channel activity. In Xenopus oocytes, arachidonic acid (AA) (20:4) reduces the activity of PANX1 channels [57]. However, in PMN, linoleic acid (LA) (18:3) induces NET formation and extracellular ATP release via the opening of PANX1 [56]. To summarize, although PANX1 mechanosensitivity is greatly influenced by the membrane lipid composition, whether it acts through a change in the membrane transbilayer pressure profile remains unstudied.

\subsection{Force-from-Filaments Model}

The alternative mechanism is that the PANX channel is gated via the cytoskeleton or extracellular matrix, which interacts with the PANX channel (Figure 1B). A study using co-immunoprecipitation and co-sedimentation assays has shown that PANX1 interacts with actin through its C-terminus [58]. Using liquid chromatography and tandem mass spectrometry (LC/MS), both actin and actin-related protein 3 (Arp3) have been identified to bind PANX1 directly [59]. A recent study has shown that, when PANX1 is overexpressed in rhabdomyosarcoma (RMS), both RNA sequencing and co-immunoprecipitation coupled to high performance liquid chromatography/electrospray ionization tandem mass spectrometry (HPLC/ES-MS) reveal that PANX1 interacts with many cytoskeleton-associated proteins physically [60].

Consistently, the inhibition of Rho kinase, Ras homolog family member A (RhoA) or myosin light chain (MLC) kinase, which disrupts the actin cytoskeleton, significantly reduces ATP release via mechanosensitive PANX1 channels [38]. Further, the treatment of Schwann cells using a Rho GTPase inhibitor or small interfering RNA (siRNA) targeting Rho or cytochalasin D results in a decrease in hypotonicity-induced ATP release via PANX1 [61]. In addition, PANX1 is associated with collapsing response mediator protein 2 (Crmp2), which is a well-known microtubule-stabilizing protein [62].

Not surprisingly, PANX1 activity in turn triggers a great deal of cellular processes involving the cytoskeleton. In C6 glioma cells, the expression of PANX1 controls the actomyosin system and accelerates the assembly of multicellular C6 glioma aggregates [63]. This effect is mediated by the release of ATP from the PANX1 channel as well as activation of the $\mathrm{P}_{2} \mathrm{X}_{7}$ receptor [63]. Another example occurs in dendritic cells (DCs); when ATP is released from injured cells, it acts as a danger signal to attract DCs to the site of injury. During this process, the actin cytoskeleton of DCs is reorganized, which is PANX1 channeland $\mathrm{P}_{2} \mathrm{X}_{7}$ receptor-dependent [64]. Further, in human skin fibroblasts, the inhibition of PANX1 enhances actin dynamics and cell motility [65]. There is a feedback mechanism 
between PANX1 and the cytoskeleton. PANX1 regulates cytoskeletal dynamics, and the cytoskeleton in turn influences PANX1 activation.

\subsection{Hybrid Model}

In fact, although the PANX1 channel can be activated by negative pressure in excised membrane patches, the cytoskeleton is still tightly associated with these membrane patches [66], so more work has to be done to confirm the inherent mechanosensitivity of the PANX1 channel. In addition, in order to comply with the force-from-lipids model, a mechanosensitive ion channel should have a domain that acts as a sensor to detect its interaction with the lipid bilayer; this domain should also connect directly to the channel pore [46,67]. Whether the PANX1 channel has this domain remains unknown.

It turns out that these two models of mechanosensitive PANX channels are not mutually exclusive. For example, no mechanoreceptor potential C (NOMPC) contains 29 ankyrin repeats, which are required for its activation by force [68]. It is also sensitive to the forcefrom-lipids paradigm. A residue of NOMPC that interacts with lipids is required for mechanically induced channel activation [69]. Conversely, the cytoskeleton and extracellular matrix also affect inherently mechanosensitive channels. TREK- 1 is intrinsically mechanosensitive, but its activity can also be modulated by cytoskeletal elements [70]. It is proposed that PANX1 gating follows the force-from-lipids model, but that the extracellular matrix and cytoskeleton can significantly affect the forces applied to PANX1.

\section{Mechanosensitive PANX1 in Physiological Processes}

\subsection{Airway Defense}

In the lung, the primary innate defense is mediated by the mucociliary clearance process, which removes foreign pathogens from the airway. Nucleotides and nucleosides act on purinergic receptors in the epithelial surface to regulate the key components of mucociliary clearance. Mechanical stress in the lung mainly comes from tidal breathing, coughing and cell swelling during hypotonic gland secretions; they can strongly stimulate ATP release in the airways via PANX1 channels. In lung epithelial cells, PANX1 is activated by hypotonically induced cell swelling [38] or hydrostatic pressure [40]. In addition, ATP release from hypotonically swollen human bronchial epithelial (HBE) cells is partially inhibited by PANX1 blockers or by knocking down the expression of PANX1 [71].

\section{2. $\mathrm{Ca}^{2+}$ Wave Signaling}

There is a positive feedback mechanism involving mechanosensitive PANX1 to mediate the initiation and propagation of intercellular $\mathrm{Ca}^{2+}$ waves. In a single layer of primary corneal endothelial cells, a $\mathrm{Ca}^{2+}$ wave is elicited by a mechanical stimulus; it propagates to the neighboring cells rapidly. PANX1 channels are implicated in this initiation and propagation of $\mathrm{Ca}^{2+}$ waves [72]. It is proposed that, when PANX1 is activated, it releases ATP from the cell. The increase in extracellular ATP activates P2Y purinergic receptors on cells within diffusion distance; P2Y receptors then stimulate phospholipase C (PLC), allowing an increase in inositol 1,4,5-triphosphate $\left(\mathrm{IP}_{3}\right)$, which induces the release of $\mathrm{Ca}^{2+}$ from intracellular stores. The increase in $\left[\mathrm{Ca}^{2+}\right]_{i}$ results in the opening of PANX1 channels and ensuing ATP release, providing a new source of ATP diffusing to cells further away (Figure 2) [22]. 


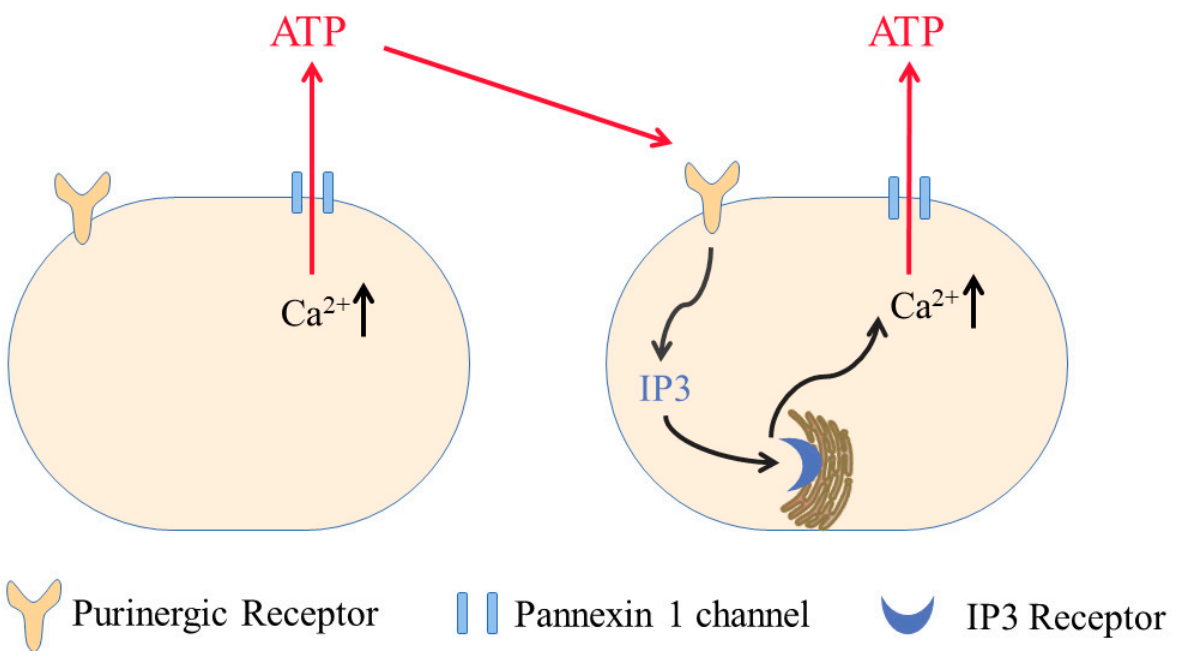

Figure 2. PANX1 is involved in the initiation and propagation of intercellular $\mathrm{Ca}^{2+}$ waves. When $\left[\mathrm{Ca}^{2+}\right]_{\mathrm{i}}$ increases in one cell, it opens PANX1 channels and releases ATP from the cell. The increase in extracellular ATP activates $\mathrm{P} 2 \mathrm{Y}$ purinergic receptors on cells within diffusion distance; P2Y receptors then stimulate phospholipase C (PLC), allowing an increase in inositol 1,4,5-triphosphate ( $\left.\mathrm{IP}_{3}\right)$, which induces the release of $\mathrm{Ca}^{2+}$ from intracellular stores. The increase in $\left[\mathrm{Ca}^{2+}\right]_{I}$ results in the opening of PANX1 channels and ensuing ATP release, providing a new source of ATP diffusing to cells further away.

\section{Mechanosensitive PANX1 in Diseases}

\subsection{Glaucoma}

Glaucoma is caused by elevated intraocular pressure (IOP) in the eye and has been associated with the death of retinal ganglion cells (RGCs). Both increased production and decreased outflow of aqueous humor within the anterior chamber result in increased IOP [73]. Positive correlations between IOP levels and RGC loss have been reported in glaucomatous rodents [74].

Recent studies have shown that PANX1 is involved in glaucoma pathogenesis $[39,75,76]$. Using ex vivo bovine eyecup preparations, an increase in pressure across the retina triggers ATP release, which can be blocked by PANX1 inhibitors [75]. A subsequent study suggested that RGCs themselves can mediate ATP release via mechanosensitive PANX1. In response to the stretching or swelling induced by hypotonic solution, RGCs can release ATP via PANX1 channels since this release is inhibited by carbenoxolone ( $\mathrm{Cbx})$, probenecid (Pbn) and ${ }^{10}$ PANX. In addition, swelling-induced current is inhibited by apyrase, A438079, $\mathrm{Cbx}$ and Pbn. ATP release via the PANX1 channel is also required for the regulatory volume decrease (RVD) of RGCs. It is proposed that excessive ATP is released when mechanosensitive PANX1 is open, which leads to the activation of purinergic receptors and induces RGC death [39].

In addition, astrocytes isolated from optic nerve heads also increase ATP release under mechanical stress; PANX1 is involved since both $\mathrm{Cbx}$ and Pbn significantly reduce ATP release. Optic nerve head astrocytes isolated from PANX1 - / - mice show deficits in both baseline and swelling-induced ATP release. RVD of astrocytes requires both PANX1 activation and the presence of extracellular ATP. Further, the expression of PANX channels is increased upon chronic stretching in isolated astrocytes and the Tg-MYOC ${ }^{\mathrm{Y} 437 \mathrm{H}}$ mouse model of chronic glaucoma [76].

\subsection{Cancer}

During metastasis, primary tumor cells enter the blood stream from their original site and are distributed throughout the whole body via the blood vessels. Around $90 \%$ of tumor cells die during this process due to mechanical stress acting upon them in blood vessels. 
Despite this hindrance, a few of these cancer cells still survive and form lethal metastatic colonies in organs.

Using a whole-transcriptomic RNA sequencing (RNA-seq) technique, Furlow et al. identified a truncated form of the PANX1 channel, PANX1 ${ }^{1-89}$, in highly metastatic human breast cancer cells. When this truncated form of PANX1 is co-expressed with wildtype full-length PANX1 channels, ATP release from the cells is significantly increased [41]. The ATP released under mechanical stress is required for the survival of metastatic cancer cells via the activation of purinergic receptors. Consistently, when the PANX1 channel is inhibited in cancer cells, these cells still survive under hypotonic stress in the presence of extracellular ATP [41]. Moreover, pharmacological inhibition of PANX1 reduces breast cancer metastasis in vivo [41]. Therefore, PANX1 channels may prove to be a therapeutic target for cancer metastasis. However, this paper does not provide a direct link between mechanosensitive PANX1 channels and cancer metastasis; more work has to be done to confirm it.

In addition, previous studies have showed that FUS stimulation has the ability to induce oscillatory $\mathrm{Ca}^{2+}$ dynamics in many invasive cell lines [77]. In invasive PC-3 cells, FUS directly activates mechanosensory PANX1 localized in the ER and results in the release of $\mathrm{Ca}^{2+}$ from the ER [42]. Ultrasound can penetrate the plasma membrane and activate the PANX1 channel in the ER membrane directly. It exerts acoustic radiation force on the membrane by increasing membrane tension or deforming the lipid bilayer [78]. Additionally, FUS stimulation induces the release of cytokines/chemokines from invasive cancer cells, indicating that FUS could be used to improve cancer immunotherapy [42].

\section{Conclusions}

Although there is a great deal of evidence to support the mechanosensitivity of the PANX1 channels, the involvement of other channels cannot be excluded. For example, leucine-rich repeat-containing protein 8 (LRRC8, also called SWELL1) channels, which are a major component of the volume regulated anion channel (VRAC), have many properties similar to those of PANX1. They are also sensitive to $\mathrm{Cbx}$ and have the ability to release ATP [79].

Furthermore, although a considerable amount of work has linked the mechanosensitivity of PANX1 to several diseases, how PANX1 channels are sensitive to the mechanical stimuli remains unknown. Furthermore, although the structure of PANX1 has been determined using cryo-EM, it does not explain the mechanism of its mechanosensitivity. It is proposed that PANX1 might have a domain that interacts with the lipid bilayer and senses the mechanical force, but further studies are required to identify it.

In addition, there are no pharmacological tools available that can be used to dissect the role of mechanosensitive PANX1. It is important to design tools to specifically block the mechanosensitive responses of the PANX1 channel, which could help us to understand the role of the mechanosensitive responses of PANX1 in many physiological processes and pathological diseases. These studies could potentially provide a therapeutic target for many diseases where the mechanosensitive activation of PANX1 channels is involved.

Author Contributions: K.Y., Z.X. and T.S. wrote the manuscript. X.H., R.W. and X.Z. revised the manuscript. Z.X. created the figures. All authors approved the final version of the manuscript.

Funding: This research was funded by the National Natural Science Foundation of China (to Taolei Sun; 51873168).

Institutional Review Board Statement: Not applicable.

Informed Consent Statement: Not applicable.

Conflicts of Interest: The authors declare no conflict of interest. 


\section{References}

1. Panchin, Y.; Kelmanson, I.; Matz, M.; Lukyanov, K.; Usman, N.; Lukyanov, S. A ubiquitous family of putative gap junction molecules. Curr. Biol. 2000, 10, R473-R474. [CrossRef]

2. Baranova, A.; Ivanov, D.; Petrash, N.; Pestova, A.; Skoblov, M.; Kelmanson, I.; Shagin, D.; Nazarenko, S.; Geraymovych, E.; Litvin, O.; et al. The mammalian pannexin family is homologous to the invertebrate innexin gap junction proteins. Genomics 2004, 83, 706-716. [CrossRef] [PubMed]

3. Penuela, S.; Bhalla, R.; Gong, X.Q.; Cowan, K.N.; Celetti, S.J.; Cowan, B.J.; Bai, D.; Shao, Q.; Laird, D.W. Pannexin 1 and Pannexin 3 are glycoproteins that exhibit many distinct characteristics from the connexin family of gap junction proteins. J. Cell Sci. 2007, 120, 3772-3783. [CrossRef] [PubMed]

4. Le Vasseur, M.; Lelowski, J.; Bechberger, J.F.; Sin, W.C.; Naus, C.C. Pannexin 2 protein expression is not restricted to the CNS. Front. Cell Neurosci. 2014, 8, 392. [CrossRef]

5. Ishikawa, M.; Iwamoto, T.; Nakamura, T.; Doyle, A.; Fukumoto, S.; Yamada, Y. Pannexin 3 functions as an ER Ca ${ }^{2+}$ channel, hemichannel, and gap junction to promote osteoblast differentiation. J. Cell Biol. 2011, 193, 1257-1274. [CrossRef]

6. Iwamoto, T.; Nakamura, T.; Ishikawa, M.; Yoshizaki, K.; Sugimoto, A.; Ida-Yonemochi, H.; Ohshima, H.; Saito, M.; Yamada, Y.; Fukumoto, S. Pannexin 3 regulates proliferation and differentiation of odontoblasts via its hemichannel activities. PLoS ONE 2017, 12, e0177557. [CrossRef]

7. Vogt, A.; Hormuzdi, S.G.; Monyer, H. Pannexin1 and Pannexin2 expression in the developing and mature rat brain. Brain Res. Mol. Brain Res. 2005, 141, 113-120. [CrossRef]

8. Deng, Z.; He, Z.; Maksaev, G.; Bitter, R.M.; Rau, M.; Fitzpatrick, J.A.J.; Yuan, P. Cryo-EM structures of the ATP release channel pannexin 1. Nat. Struct. Mol. Biol. 2020, 27, 373-381. [CrossRef]

9. Jin, Q.; Zhang, B.; Zheng, X.; Li, N.; Xu, L.; Xie, Y.; Song, F.; Bhat, E.A.; Chen, Y.; Gao, N.; et al. Cryo-EM structures of human pannexin 1 channel. Cell Res. 2020, 30, 449-451. [CrossRef]

10. Michalski, K.; Syrjanen, J.L.; Henze, E.; Kumpf, J.; Furukawa, H.; Kawate, T. The cryo-EM structure of Pannexin 1 reveals unique motifs for ion selection and inhibition. eLife 2020, 9, e54670. [CrossRef]

11. Mou, L.; Ke, M.; Song, M.; Shan, Y.; Xiao, Q.; Liu, Q.; Li, J.; Sun, K.; Pu, L.; Guo, L.; et al. Structural basis for gating mechanism of Pannexin 1 channel. Cell Res. 2020, 30, 452-454. [CrossRef] [PubMed]

12. Qu, R.; Dong, L.; Zhang, J.; Yu, X.; Wang, L.; Zhu, S. Cryo-EM structure of human heptameric Pannexin 1 channel. Cell Res. 2020, 30, 446-448. [CrossRef] [PubMed]

13. Ruan, Z.; Orozco, I.J.; Du, J.; Lu, W. Structures of human pannexin 1 reveal ion pathways and mechanism of gating. Nature 2020, 584, 646-651. [CrossRef] [PubMed]

14. Ambrosi, C.; Gassmann, O.; Pranskevich, J.N.; Boassa, D.; Smock, A.; Wang, J.; Dahl, G.; Steinem, C.; Sosinsky, G.E. Pannexin1 and Pannexin2 channels show quaternary similarities to connexons and different oligomerization numbers from each other. $J$. Biol. Chem. 2010, 285, 24420-24431. [CrossRef] [PubMed]

15. Wang, J.; Ambrosi, C.; Qiu, F.; Jackson, D.G.; Sosinsky, G.; Dahl, G. The membrane protein Pannexin1 forms two open-channel conformations depending on the mode of activation. Sci. Signal. 2014, 7, ra69. [CrossRef]

16. Dahl, G. The Pannexin1 membrane channel: Distinct conformations and functions. FEBS Lett. 2018, 592, 3201-3209. [CrossRef]

17. Sabirov, R.Z.; Okada, Y. Wide nanoscopic pore of maxi-anion channel suits its function as an ATP-conductive pathway. Biophys. J. 2004, 87, 1672-1685. [CrossRef]

18. Silverman, W.R.; de Rivero Vaccari, J.P.; Locovei, S.; Qiu, F.; Carlsson, S.K.; Scemes, E.; Keane, R.W.; Dahl, G. The pannexin 1 channel activates the inflammasome in neurons and astrocytes. J. Biol. Chem. 2009, 284, 18143-18151. [CrossRef]

19. Jackson, D.G.; Wang, J.; Keane, R.W.; Scemes, E.; Dahl, G. ATP and potassium ions: A deadly combination for astrocytes. Sci. Rep. 2014, 4, 4576. [CrossRef]

20. Wang, J.; Jackson, D.G.; Dahl, G. Cationic control of Panx1 channel function. Am. J. Physiol. Cell Physiol. 2018, 315, C279-C289. [CrossRef]

21. Chiu, Y.H.; Jin, X.; Medina, C.B.; Leonhardt, S.A.; Kiessling, V.; Bennett, B.C.; Shu, S.; Tamm, L.K.; Yeager, M.; Ravichandran, K.; et al. A quantized mechanism for activation of pannexin channels. Nat. Commun. 2017, 8, 14324. [CrossRef] [PubMed]

22. Locovei, S.; Wang, J.; Dahl, G. Activation of pannexin 1 channels by ATP through P2Y receptors and by cytoplasmic calcium. FEBS Lett. 2006, 580, 239-244. [CrossRef] [PubMed]

23. Wang, S.; Chennupati, R.; Kaur, H.; Iring, A.; Wettschureck, N.; Offermanns, S. Endothelial cation channel PIEZO1 controls blood pressure by mediating flow-induced ATP release. J. Clin. Investig. 2016, 126, 4527-4536. [CrossRef] [PubMed]

24. Diem, K.; Fauler, M.; Fois, G.; Hellmann, A.; Winokurow, N.; Schumacher, S.; Kranz, C.; Frick, M. Mechanical stretch activates piezo1 in caveolae of alveolar type I cells to trigger ATP release and paracrine stimulation of surfactant secretion from alveolar type II cells. FASEB J. 2020, 34, 12785-12804. [CrossRef] [PubMed]

25. Desplat, A.; Penalba, V.; Gros, E.; Parpaite, T.; Coste, B.; Delmas, P. Piezo1-Pannexin1 complex couples force detection to ATP secretion in cholangiocytes. J. Gen. Physiol. 2021, 153, e202112871. [CrossRef]

26. Lopez, X.; Palacios-Prado, N.; Guiza, J.; Escamilla, R.; Fernandez, P.; Vega, J.L.; Rojas, M.; Marquez-Miranda, V.; Chamorro, E.; Cárdenas, A.M.; et al. A physiologic rise in cytoplasmic calcium ion signal increases pannexin1 channel activity via a C-terminus phosphorylation by CaMKII. Proc. Natl. Acad Sci. USA 2021, 118, e2108967118. [CrossRef] 
27. Iglesias, R.; Locovei, S.; Roque, A.; Alberto, A.P.; Dahl, G.; Spray, D.C.; Scemes, E. P2X7 receptor-pannexin1 complex: Pharmacology and signaling. Am. J. Physiol. Cell Physiol. 2008, 295, C752-C760. [CrossRef]

28. Thompson, R.J.; Jackson, M.F.; Olah, M.E.; Rungta, R.L.; Hines, D.J.; Beazely, M.A.; MacDonald, J.F.; MacVicar, B.A. Activation of pannexin-1 hemichannels augments aberrant bursting in the hippocampus. Science 2008, 322, 1555-1559. [CrossRef]

29. Lohman, A.W.; Leskov, I.L.; Butcher, J.T.; Johnstone, S.R.; Stokes, T.A.; Begandt, D.; DeLalio, L.; Best, A.K.; Penuela, S.; Leitinger, N.; et al. Pannexin 1 channels regulate leukocyte emigration through the venous endothelium during acute inflammation. Nat. Commun. 2015, 6, 7965. [CrossRef]

30. Thompson, R.J.; Zhou, N.; MacVicar, B.A. Ischemia opens neuronal gap junction hemichannels. Science 2006, 312, 924-927. [CrossRef]

31. Weilinger, N.L.; Tang, P.L.; Thompson, R.J. Anoxia-induced NMDA receptor activation opens pannexin channels via Src family kinases. J. Neurosci. 2012, 32, 12579-12588. [CrossRef] [PubMed]

32. Weilinger, N.L.; Lohman, A.W.; Rakai, B.D.; Ma, E.M.; Bialecki, J.; Maslieieva, V.; Rilea, T.; Bandet, M.V.; Ikuta, N.T.; Scott, L.; et al. Metabotropic NMDA receptor signaling couples Src family kinases to pannexin-1 during excitotoxicity. Nat. Neurosci. 2016, 19, 432-442. [CrossRef] [PubMed]

33. Chekeni, F.B.; Elliott, M.R.; Sandilos, J.K.; Walk, S.F.; Kinchen, J.M.; Lazarowski, E.R.; Armstrong, A.J.; Penuela, S.; Laird, D.W.; Salvesen, G.S.; et al. Pannexin 1 channels mediate 'find-me' signal release and membrane permeability during apoptosis. Nature 2010, 467, 863-867. [CrossRef] [PubMed]

34. Sandilos, J.K.; Chiu, Y.H.; Chekeni, F.B.; Armstrong, A.J.; Walk, S.F.; Ravichandran, K.S.; Bayliss, D.A. Pannexin 1, an ATP release channel, is activated by caspase cleavage of its pore-associated C-terminal autoinhibitory region. J. Biol. Chem. 2012, 287, 11303-11311. [CrossRef] [PubMed]

35. Yang, D.; He, Y.; Munoz-Planillo, R.; Liu, Q.; Nunez, G. Caspase-11 requires the pannexin-1 channel and the purinergic P2X7 pore to mediate pyroptosis and endotoxic shock. Immunity 2015, 43, 923-932. [CrossRef] [PubMed]

36. Bao, L.; Locovei, S.; Dahl, G. Pannexin membrane channels are mechanosensitive conduits for ATP. FEBS Lett. 2004, 572, 65-68. [CrossRef]

37. Locovei, S.; Bao, L.; Dahl, G. Pannexin 1 in erythrocytes: Function without a gap. Proc. Natl. Acad. Sci. USA 2006, 103, 7655-7659. [CrossRef]

38. Seminario-Vidal, L.; Okada, S.F.; Sesma, J.I.; Kreda, S.M.; van Heusden, C.A.; Zhu, Y.; Jones, L.C.; O’Neal, W.K.; Penuela, S.; Laird, D.W.; et al. Rho signaling regulates pannexin 1-mediated ATP release from airway epithelia. J. Biol. Chem. 2011, 286, 26277-26286. [CrossRef]

39. Xia, J.; Lim, J.C.; Lu, W.; Beckel, J.M.; Macarak, E.J.; Laties, A.M.; Mitchell, C.H. Neurons respond directly to mechanical deformation with pannexin-mediated ATP release and autostimulation of P2X7 receptors. J. Physiol. 2012, 590, 2285-2304. [CrossRef]

40. Richter, K.; Kiefer, K.P.; Grzesik, B.A.; Clauss, W.G.; Fronius, M. Hydrostatic pressure activates ATP-sensitive $\mathrm{K}^{+}$channels in lung epithelium by ATP release through pannexin and connexin hemichannels. FASEB J. 2014, 28, 45-55. [CrossRef]

41. Furlow, P.W.; Zhang, S.; Soong, T.D.; Halberg, N.; Goodarzi, H.; Mangrum, C.; Wu, Y.G.; Elemento, O.; Tavazoie, S.F. Mechanosensitive pannexin-1 channels mediate microvascular metastatic cell survival. Nat. Cell Biol. 2015, 17, 943-952. [CrossRef]

42. Lee, N.S.; Yoon, C.W.; Wang, Q.; Moon, S.; Koo, K.M.; Jung, H.; Chen, R.; Jiang, L.; Lu, G.; Fernandez, A.; et al. Focused ultrasound stimulates ER localized mechanosensitive PANNEXIN-1 to mediate intracellular calcium release in invasive cancer cells. Front. Cell Dev. Biol. 2020, 8, 504. [CrossRef] [PubMed]

43. Martinac, B.; Adler, J.; Kung, C. Mechanosensitive ion channels of E. coli activated by amphipaths. Nature 1990, 348, 261-263. [CrossRef] [PubMed]

44. Markin, V.S.; Martinac, B. Mechanosensitive ion channels as reporters of bilayer expansion. A theoretical model. Biophys. J. 1991, 60, 1120-1127. [CrossRef]

45. Martinac, B.; Rohde, P.R.; Battle, A.R.; Petrov, E.; Pal, P.; Foo, A.F.; Vásquez, V.; Huynh, T.; Kloda, A. Studying mechanosensitive ion channels using liposomes. Methods Mol. Biol. 2010, 606, 31-53. [CrossRef]

46. Martinac, B.; Bavi, N.; Ridone, P.; Nikolaev, Y.A.; Martinac, A.D.; Nakayama, Y.; Rohde, P.R.; Bavi, O. Tuning ion channel mechanosensitivity by asymmetry of the transbilayer pressure profile. Biophys. Rev. 2018, 10, 1377-1384. [CrossRef]

47. Cantor, R.S. Lipid composition and the lateral pressure profile in bilayers. Biophys. J. 1999, 76, 2625-2639. [CrossRef]

48. Cox, C.D.; Bavi, N.; Martinac, B. Biophysical principles of ion-channel-mediated mechanosensory transduction. Cell Rep. 2019, 29, 1-12. [CrossRef]

49. Perozo, E.; Kloda, A.; Cortes, D.M.; Martinac, B. Physical principles underlying the transduction of bilayer deformation forces during mechanosensitive channel gating. Nat. Struct. Biol. 2002, 9, 696-703. [CrossRef]

50. Gullingsrud, J.; Schulten, K. Lipid bilayer pressure profiles and mechanosensitive channel gating. Biophys. J. 2004, 86, 3496-3509. [CrossRef]

51. Ridone, P.; Grage, S.L.; Patkunarajah, A.; Battle, A.R.; Ulrich, A.S.; Martinac, B. Force-from-lipids gating of mechanosensitive channels modulated by PUFAs. J. Mech. Behav. Biomed. Mater. 2018, 79, 158-167. [CrossRef] [PubMed]

52. Xiao, F.; Waldrop, S.L.; Khimji, A.K.; Kilic, G. Pannexin1 contributes to pathophysiological ATP release in lipoapoptosis induced by saturated free fatty acids in liver cells. Am. J. Physiol. Cell Physiol. 2012, 303, C1034-C1044. [CrossRef] [PubMed] 
53. Sun, H.; Sun, Z.; Varghese, Z.; Guo, Y.; Moorhead, J.F.; Unwin, R.J.; Ruan, X.Z. Nonesterified free fatty acids enhance the inflammatory response in renal tubules by inducing extracellular ATP release. Am. J. Physiol. Renal Physiol. 2020, 319, F292-F303. [CrossRef] [PubMed]

54. Tam, T.H.; Chan, K.L.; Boroumand, P.; Liu, Z.; Brozinick, J.T.; Bui, H.H.; Roth, K.; Wakefield, C.B.; Penuela, S.; Bilan, P.J.; et al. Nucleotides released from palmitate-activated murine macrophages attract neutrophils. J. Biol. Chem. 2020, $295,4902-4911$. [CrossRef] [PubMed]

55. Pillon, N.J.; Li, Y.E.; Fink, L.N.; Brozinick, J.T.; Nikolayev, A.; Kuo, M.S.; Bilan, P.J.; Klip, A. Nucleotides released from palmitatechallenged muscle cells through pannexin-3 attract monocytes. Diabetes 2014, 63, 3815-3826. [CrossRef] [PubMed]

56. Alarcon, P.; Manosalva, C.; Quiroga, J.; Belmar, I.; Alvarez, K.; Diaz, G.; Taubert, A.; Hermosilla, C.; Carretta, M.D.; Burgos, R.A.; et al. Oleic and linoleic acids induce the release of neutrophil extracellular traps via pannexin 1-dependent ATP release and P2X1 receptor activation. Front. Vet. Sci. 2020, 7, 260. [CrossRef]

57. Samuels, S.E.; Lipitz, J.B.; Wang, J.; Dahl, G.; Muller, K.J. Arachidonic acid closes innexin/pannexin channels and thereby inhibits microglia cell movement to a nerve injury. Dev. Neurobiol. 2013, 73, 621-631. [CrossRef]

58. Bhalla-Gehi, R.; Penuela, S.; Churko, J.M.; Shao, Q.; Laird, D.W. Pannexin1 and pannexin3 delivery, cell surface dynamics, and cytoskeletal interactions. J. Biol. Chem. 2010, 285, 9147-9160. [CrossRef]

59. Wicki-Stordeur, L.E.; Swayne, L.A. Panx1 regulates neural stem and progenitor cell behaviours associated with cytoskeletal dynamics and interacts with multiple cytoskeletal elements. Cell. Commun. Signal. 2013, 11, 62. [CrossRef]

60. Xiang, X.; Langlois, S.; St-Pierre, M.E.; Blinder, A.; Charron, P.; Graber, T.E.; Fowler, S.L.; Baird, S.D.; Bennett, S.A.L.; Alain, T.; et al. Identification of pannexin 1-regulated genes, interactome, and pathways in rhabdomyosarcoma and its tumor inhibitory interaction with AHNAK. Oncogene 2021, 40, 1868-1883. [CrossRef]

61. Wei, Z.Y.; Qu, H.L.; Dai, Y.J.; Wang, Q.; Ling, Z.M.; Su, W.F.; Zhao, Y.-Y.; Shen, W.-X. Pannexin 1, a large-pore membrane channel, contributes to hypotonicity-induced ATP release in Schwann cells. Neural Regen. Res. 2021, 16, 899-904. [CrossRef] [PubMed]

62. Xu, X.; Wicki-Stordeur, L.E.; Sanchez-Arias, J.C.; Liu, M.; Weaver, M.S.; Choi, C.S.W.; Swayne, L.A. Probenecid disrupts a novel Pannexin 1-collapsin response mediator protein 2 interaction and increases microtubule stability. Front. Cell Neurosci. 2018, 12, 124. [CrossRef] [PubMed]

63. Bao, B.A.; Lai, C.P.; Naus, C.C.; Morgan, J.R. Pannexin1 drives multicellular aggregate compaction via a signaling cascade that remodels the actin cytoskeleton. J. Biol. Chem. 2012, 287, 8407-8416. [CrossRef] [PubMed]

64. Saez, P.J.; Vargas, P.; Shoji, K.F.; Harcha, P.A.; Lennon-Dumenil, A.M.; Saez, J.C. ATP promotes the fast migration of dendritic cells through the activity of pannexin 1 channels and P2X7 receptors. Sci. Signal. 2017, 10, eaah7107. [CrossRef]

65. Flores-Munoz, C.; Maripillan, J.; Vasquez-Navarrete, J.; Novoa-Molina, J.; Ceriani, R.; Sanchez, H.A.; Abbott, A.; WeinsteinOppenheimer, C.; Brown, D.; Cárdenas, A.; et al. Restraint of human skin fibroblast motility, migration, and cell surface actin dynamics, by Pannexin 1 and P2X7 receptor signaling. Int. J. Mol. Sci. 2021, 22, 1069. [CrossRef]

66. Hamill, O.P. Twenty odd years of stretch-sensitive channels. Pflugers Arch. 2006, 453, 333-351. [CrossRef]

67. Teng, J.; Loukin, S.; Anishkin, A.; Kung, C. The force-from-lipid (FFL) principle of mechanosensitivity, at large and in elements. Pflugers Arch. 2015, 467, 27-37. [CrossRef]

68. Zhang, W.; Cheng, L.E.; Kittelmann, M.; Li, J.; Petkovic, M.; Cheng, T.; Jin, P.; Guo, Z.; Göpfert, M.C.; Jan, L.; et al. Ankyrin repeats convey force to gate the NOMPC mechanotransduction channel. Cell 2015, 162, 1391-1403. [CrossRef]

69. Jin, P.; Bulkley, D.; Guo, Y.; Zhang, W.; Guo, Z.; Huynh, W.; Wu, S.; Meltzer, S.; Cheng, T.; Jan, L.; et al. Electron cryo-microscopy structure of the mechanotransduction channel NOMPC. Nature 2017, 547, 118-122. [CrossRef]

70. Li Fraine, S.; Patel, A.; Duprat, F.; Sharif-Naeini, R. Dynamic regulation of TREK1 gating by polycystin 2 via a filamin A-mediated cytoskeletal mechanism. Sci. Rep. 2017, 7, 17403. [CrossRef]

71. Ransford, G.A.; Fregien, N.; Qiu, F.; Dahl, G.; Conner, G.E.; Salathe, M. Pannexin 1 contributes to ATP release in airway epithelia. Am. J. Respir. Cell Mol. Biol. 2009, 41, 525-534. [CrossRef] [PubMed]

72. D'hondt, C.; Himpens, B.; Bultynck, G. Mechanical stimulation-induced calcium wave propagation in cell monolayers: The example of bovine corneal endothelial cells. J. Vis. Exp. 2013, 77, e50443. [CrossRef] [PubMed]

73. Stamer, W.D.; Acott, T.S. Current understanding of conventional outflow dysfunction in glaucoma. Curr. Opin. Ophthalmol. 2012, 23, 135-143. [CrossRef] [PubMed]

74. John, S.W.; Smith, R.S.; Savinova, O.V.; Hawes, N.L.; Chang, B.; Turnbull, D.; Davisson, M.; Roderick, T.H.; Heckenlively, J.R Essential iris atrophy, pigment dispersion, and glaucoma in DBA/2J mice. Investig. Ophthalmol. Vis. Sci. 1998, 39, 951-962.

75. Reigada, D.; Lu, W.; Zhang, M.; Mitchell, C.H. Elevated pressure triggers a physiological release of ATP from the retina: Possible role for pannexin hemichannels. Neuroscience 2008, 157, 396-404. [CrossRef]

76. Beckel, J.M.; Argall, A.J.; Lim, J.C.; Xia, J.; Lu, W.; Coffey, E.E.; Macarak, E.J.; Shahidullah, M.; Delamere, N.; Zode, G.S.; et al Mechanosensitive release of adenosine $5^{\prime}$-triphosphate through pannexin channels and mechanosensitive upregulation of pannexin channels in optic nerve head astrocytes: A mechanism for purinergic involvement in chronic strain. Glia 2014, 62, 1486-1501. [CrossRef]

77. Weitz, A.C.; Lee, N.S.; Yoon, C.W.; Bonyad, A.; Goo, K.S.; Kim, S.; Moon, S.; Jung, H.; Zhou, Q.; Chow, R.H.; et al. Functional assay of cancer cell invasion potential based on mechanotransduction of focused ultrasound. Front. Oncol. 2017, 7, 161. [CrossRef] 
78. Dalecki, D. Mechanical bioeffects of ultrasound. Annu. Rev. Biomed. Eng. 2004, 6, 229-248. [CrossRef]

79. Gaitan-Penas, H.; Gradogna, A.; Laparra-Cuervo, L.; Solsona, C.; Fernandez-Duenas, V.; Barrallo-Gimeno, A.; Ciruela, F.; Lakadamyali, M.; Pusch, M.; Estévez, R. Investigation of LRRC8-mediated volume-regulated anion currents in Xenopus oocytes. Biophys. J. 2016, 111, 1429-1443. [CrossRef] 